\title{
Outcome of 20-gauge transconjunctival cannulated sutureless vitrectomy using silicone oil or air tamponade
}

This article was published in the following Dove Press journal:

Clinical Ophthalmology

18 February 2013

Number of times this article has been viewed

\author{
Ahmed Abdel Alim \\ Mohamed' \\ Mohamed Abdrabbo² \\ 'Ain Shams University, Faculty of \\ Medicine, Ophthalmology Department, \\ Cairo; ${ }^{2}$ Faculty of Medicine, \\ Ophthalmology Department, Benha \\ University, Benha, Egypt
}

Background: The purpose of this study was to assess the outcome of pars plana vitrectomy using a 20-gauge transconjunctival cannulated sutureless system with air or silicone oil tamponade in cases of retinal detachment of different etiologies.

Methods: A prospective study was performed in 60 eyes from consecutive 60 patients who underwent 20-gauge transconjunctival cannulated sutureless vitrectomy (30 eyes with air tamponade and 30 eyes with silicone oil tamponade), with the inclusion of a further 30 patients who underwent conventional 20-gauge vitrectomy and served as a control group. The main outcome measures were intraocular pressure, wound leakage, and comfort score.

Results: Preoperative intraocular pressure increased from $17.67 \pm 5.6 \mathrm{mmHg}$ preoperatively to $18.78 \pm 6.1 \mathrm{mmHg}$ on the first postoperative day in group A and decreased from $16.97 \pm 4.9 \mathrm{mmHg}$ to $15.88 \pm 5.3 \mathrm{mmHg}$ in group B. These changes were not statistically significant $(P>0.05)$. The comfort score ranged from 1 to $5(1=$ very bad, $2=$ bad, $3=$ good, $4=$ very good, and $5=$ excellent), with a mean of $4.4 \pm 0.94$ in group A and $4.35 \pm 0.99$ in group B on the first postoperative day, and no significant difference in scores between the groups at any follow-up visit. There was intraoperative wound leakage in two cases $(6.7 \%)$ in group A which required suturing and one case $(3.3 \%)$ in group B, but the difference was not statistically significant $(P>0.05)$. There was no wound leakage at follow-up in either group. No cases of hypotony, endophthalmitis, or unsealed sclerotomies were noted.

Conclusion: Pars plana vitrectomy using a 20-gauge transconjunctival cannulated sutureless system combines the advantages of smaller-gauge vitrectomy systems with the economic advantage of not needing to purchase any additional handheld instruments. It can be used with both air and silicone oil tamponade in most cases of retinal detachment.

Keywords: 20-gauge transconjunctival cannulated sutureless system, intraocular pressure, wound leakage

\section{Introduction}

Since the introduction of pars plana vitrectomy, evolution of instrumentation has been driven by the desire for smaller instruments and greater functionality. Smaller vitrectomy instruments may minimize surgical trauma at sclerostomy sites, allowing self-sealing sclerostomies, which may improve surgical efficiency and postoperative recovery. ${ }^{1}$

A number of problems have been identified with conventional 20-gauge pars plana vitrectomy, including iatrogenic retinal breaks, particularly those associated with sclerostomy, ie, entry site breaks. The risk of entry site breaks is considered to be related to repeated entry and exit of instruments through the sclerostomy site, and consequent
Correspondence: Ahmed Abdel Alim Mohamed

Ain Shams University, Faculty of Medicine, Ophthalmology Department, Cairo, Egypt

Tel +2 01009650088

Email mohamedabdrabbo@yahoo.com 
damage to the vitreous base. Machemer and Hickingbotham ${ }^{2}$ introduced a system of cannulae which were inserted through the sclerostomy for the duration of the procedure. These allowed repeated insertion and removal of 20 -gauge instruments, while minimizing trauma to the vitreous base.

The need to suture sclerostomies is considered to be the time-consuming part of the surgical procedure, so a number of suggestions have been made to reduce the requirement for suturing. Hilton ${ }^{3}$ described a sutureless self-retaining infusion cannula in 1985, and a modification of this technique was reported in $1990 .{ }^{4}$ In 1996 , Chen ${ }^{5}$ described a method for producing a self-sealing sclerostomy, which involved creating a shallow scleral pocket (posteriorly to anteriorly), with entry into the vitreous from the top of the pocket. No complications were encountered in a series of 50 patients, and the wounds were self-sealing and required no scleral sutures in 47 cases. Chen recommended the technique firstly on the basis of avoiding sutures, and secondly, because of the improved control over intraoperative ocular pressure. No claims were made of faster recovery or increased patient comfort, presumably because conjunctival sutures were still required and these are the primary cause of any postoperative discomfort.

Assi et $\mathrm{al}^{6}$ advised rotating the pocket by an additional 90 degrees, so that the pocket could be accessed anteriorly. They also used a pocket knife to fashion a pouch, reporting the results of 50 sclerostomies in 25 eyes. Suturing was required in three cases, and there was "limited choroidal hemorrhage" associated with introduction of the infusion cannula in one case. There were also two entry site retinal tears, but no postoperative complications related to the technique itself.

Proponents of the sutureless sclerostomy claim that the advantages are reduced operative time, less risk of perioperative hypotony upon removal of instruments, and less postoperative inflammation. However, these advantages are unproven, and none of the reported techniques has gained widespread popularity, probably because there still remains the requirement to suture the conjunctiva.

Owing to the small incision involved and the lack of need to suture, 25-gauge transconjunctival sutureless vitrectomy enables minimization of surgical trauma, avoidance of suturerelated inflammation, and faster postoperative recovery. However, many vitreoretinal surgeons use it only in limited indications due to the inherent high flexibility of 25-gauge instruments. $^{7}$

Transconjunctival sutureless vitrectomy with a 23-gauge instrument, introduced by Eckardt in 2005, offers a firmer instrument and is easily used by the vitreous surgeon more familiar with the 20-gauge instrument than the 25-gauge instrument. This advantage may help the surgeon converting from 20-gauge vitrectomy to transconjunctival sutureless vitrectomy with a 23-gauge instrument. ${ }^{8}$

However, various complications have been reported, including postoperative hypotony due to the nonsuturing system used and a higher risk of endophthalmitis. ${ }^{9}$ Further, neither 23-gauge nor 25-gauge transconjunctival sutureless vitrectomy is suitable in some cases, e.g. the increased cost when silicone oil is used. ${ }^{10}$ Here we report the technique and our initial clinical experience with transconjunctival 20 -gauge vitrectomy using the Claes 20 -gauge vitrectomy system with silicone oil or air tamponade.

\section{Patients and methods}

This prospective, randomized, controlled clinical trial included a control group $(n=30)$ of eyes treated with conventional 20-gauge vitrectomy, a group treated with the 20-gauge transconjunctival cannulated sutureless system in an eye filled with silicone oil (group A, $n=30$ ) or air (group B, $n=30$ ). Patients were fully informed of all aspects of the procedure, and all provided their written informed consent. Ethics committee approval was obtained. All procedures were performed by the same surgeon (MA). Information on patient age and gender are summarized in Table 1. Surgery was indicated for various vitreoretinal disorders, including proliferative diabetic retinopathy, rhegmatogenous retinal detachment, macular surgery, epiretinal membrane, and vitreous hemorrhage due to retinal vein occlusion, as shown in Table 2. Exclusion criteria included vitreoretinal disorders in children younger than 15 years and traumatic cases. There was no statistical significant difference between the groups with regard to distribution of diagnoses. Conventional sutured 20-gauge vitrectomy was performed in the control group with either silicone oil $(n=18)$ or air $(n=12)$. We used the 1270-C20 20-gauge

Table I Age and gender distribution of the study groups

\begin{tabular}{llll}
\hline Variables & $\begin{array}{l}\text { Control } \\
\text { group }\end{array}$ & $\begin{array}{l}\text { Group A } \\
\text { (silicone-filled) }\end{array}$ & $\begin{array}{l}\text { Group B } \\
\text { (air-filled) }\end{array}$ \\
\hline $\begin{array}{l}\text { Gender } \\
\quad \text { Male }\end{array}$ & $18(60 \%)$ & $21(70 \%)$ & $20(66.7 \%)$ \\
$\quad \begin{array}{l}\text { Female } \\
\text { Total number of cases }\end{array}$ & $12(40 \%)$ & $9(30 \%)$ & $10(33.3 \%)$ \\
$\begin{array}{l}\text { Age, years } \\
\quad \text { Range }\end{array}$ & 30 & 30 \\
$\quad \begin{array}{l}\text { Mean } \pm \text { standard } \\
\text { deviation }\end{array}$ & $43-72$ & $25-68$ & $47-66$ \\
\hline
\end{tabular}


Table 2 Distribution of cases with regard to diagnosis and percentages

\begin{tabular}{|c|c|c|c|c|c|c|}
\hline \multirow[t]{2}{*}{ Diagnosis } & \multicolumn{2}{|c|}{ Group A } & \multicolumn{2}{|c|}{ Group B } & \multicolumn{2}{|c|}{$\begin{array}{l}\text { Control } \\
\text { group }\end{array}$} \\
\hline & $\mathbf{n}$ & $\%$ & $\mathbf{n}$ & $\%$ & $\mathbf{n}$ & $\%$ \\
\hline Macular hole & 0 & 0 & 5 & 5 & 5 & 16 \\
\hline GRB & 2 & 6.7 & 7 & 7 & 7 & 23 \\
\hline MH RD & I & 3.3 & 2 & 2 & 2 & 6.7 \\
\hline PDR & 9 & 30 & 0 & 0 & 0 & 0 \\
\hline PDR cat & 0 & 0 & 3 & 3 & 3 & 10 \\
\hline PDR TRD & 2 & 6.7 & 1 & 1 & I & 3.3 \\
\hline DR rec & 2 & 6.7 & 1 & 1 & I & 3.3 \\
\hline RD rec & 3 & 10 & I & I & I & 3.3 \\
\hline RRD & 9 & 30 & 4 & 4 & 4 & 13 \\
\hline TRD & 2 & 6.7 & 2 & 2 & 2 & 6.7 \\
\hline Vit $\mathrm{Hg}$ & 0 & 0 & 3 & 3 & 3 & 10 \\
\hline Vit Hg CRVO & 0 & 0 & 1 & 1 & 1 & 3.3 \\
\hline Total & 30 & 100 & 30 & 30 & 30 & 100 \\
\hline$P$ & \multicolumn{6}{|c|}{$\chi^{2}=12.29, P=0.3425$} \\
\hline
\end{tabular}

Abbreviations: cat, cataract; CRVO, central retinal vein occlusion; GRB, giant retina breaks; MH RD, retinal detachment and macular hole; PDR, proliferative diabetic retinopathy; TDR, tractional retinal detachment; RRD, rhegmatogenous retina detachment; Vit $\mathrm{Hg}$, vitreous hemorrhage; DR rec, recurrent diabetic retinopathy; RD rec, recurrent retinal detachment.

vitrectomy system with closed valves developed by Clae, as shown in Figure 2.

The surgical technique consisted of placement of three sclerostomies $3.5 \mathrm{~mm}$ and $4.0 \mathrm{~mm}$ behind the limbus in pseudophakic eyes and aphakic/phakic eyes, respectively, through the conjunctiva and sclera in one step. A bent 20-gauge bevelled MVR blade was used with a tangential approach (15 degrees) to create a combined conjunctivoscleral tunnel incision in the inferotemporal quadrant (Figure 3). The conjunctiva was dragged with Barakar forceps slightly before creating the scleral tunnel to ensure the conjunctival wound was not at the same site as the scleral wound (Figure 4).

After insertion of the sleeve via a trocar through the sclerotomy followed by insertion of the infusion cannula, the superotemporal and superonasal conjunctival sclerostomies were then created. The intraoperative appearance of the trocar-cannula system is shown in Figure 5. Vitrectomy was performed through these sclerostomies with conventional 20 -gauge instruments, including vitreous cutters, light pipes, straight scissors, and end-grabbing forceps. After injection of silicon in group A and air in group B, the sleeve was removed, leaving the wound sutureless. The area over the port was massaged immediately with a cotton tip to allow the scleral flaps of the tunnel to expand and collapse one over the other to avoid leak at the entry port.

For eyes in which air tamponade was used, the trocar was removed with air pressure at $10-15 \mathrm{mmHg}$, and the air pressure is then increased by injection using an insulin syringe.
For eyes in which silicone oil was used (group A), there was no leak due to the higher viscosity of the oil. A few eyes in which air tamponade was used (group B) showed a small amount of air leak at the end of the procedure. Subconjunctival antibiotics and corticosteroids were administered at the end of the procedure.

The patients were followed up at one day, one week, 2 weeks, and at one, 2, 4, and 6 months after surgery. Preoperative and postoperative examinations included Goldmann applanation tonometry and slit-lamp biomicroscopy. Foreign body sensation, pain, and chemosis were graded in each patient postoperatively. Postoperative outcome measurements included intraocular pressure, wound leakage, and a comfort score from 1 to $5(1=$ very bad, $2=$ bad, $3=$ good, $4=$ very good, and $5=$ excellent).

\section{Results}

\section{Postoperative intraocular pressure}

In the control group, intraocular pressure increased from $19.32 \pm 5.4 \mathrm{mmHg}$ preoperatively to $22.2 \pm 7.3 \mathrm{mmHg}$ on the first postoperative day in group A, and from $18.4 \pm 3 \mathrm{mmHg}$ to $17.5 \pm 6.1 \mathrm{mmHg}$ in group B. At postoperative week 2, intraocular pressure decreased to $18.3 \pm 2.1 \mathrm{mmHg}$ in group $\mathrm{A}$ and to $16.5 \pm 3.4 \mathrm{mmHg}$ in group $\mathrm{B}$, with no statistically significant changes seen between day 1 and week $2(P>0.05)$. No significant changes in intraocular pressure occurred between week 2 and month 6 .

In the sutureless vitrectomy groups, intraocular pressure increased from $17.67 \pm 5.6 \mathrm{mmHg}$ preoperatively to $18.78 \pm 6.1 \mathrm{mmHg}$ on the first postoperative day in group A and decreased from $16.97 \pm 4.9 \mathrm{mmHg}$ preoperatively to $15.88 \pm 5.3 \mathrm{mmHg}$ on the first postoperative day in group B. These differences were not statistically significant $(P>0.05)$, but the difference was highly significant at week 2 and at months 2, 4, and 6, with group A recording higher intraocular pressures than group B. This difference between the treatment groups for mean postoperative intraocular pressures during the follow-up period is shown in Figure 1.

Comparing the postoperative change in intraocular pressure between the conventional silicone-filled (control) and sutureless silicone-filled (group A) and between conventional air-filled (control) and sutureless air-filled (group B) vitrectomies, there was a statistically significant change between day 1 and week $2(P<0.05)$, with higher levels of postoperative intraocular pressure in the control group. After week 2, the change was not statistically significant $(P>0.05)$ and remained insignificant at month 6 . 


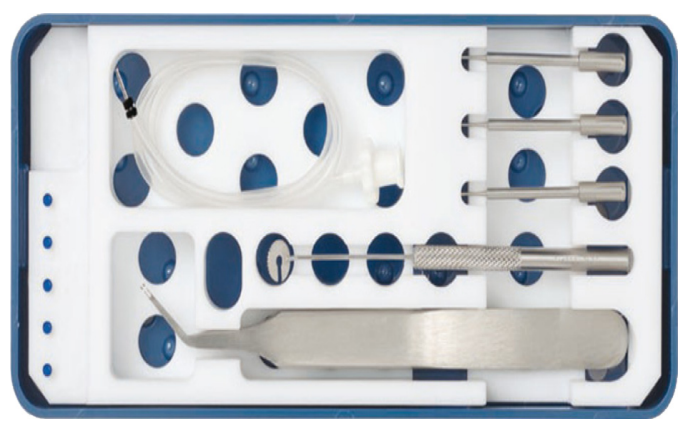

Figure I Claes 20-gauge vitrectomy system.

\section{Comfort score}

In the control group, the mean comfort score was $2.8 \pm 0.8$ on the first postoperative day in the silicone-filled group and $3.1 \pm 0.34$ on the first postoperative day in the air-filled group, with no significant difference between the groups for comfort score at any of the follow-up visits. In the sutureless groups, the mean comfort score was $4.4 \pm 0.94$ on the first postoperative day in group $A$ and $4.35 \pm 0.99$ on the first postoperative day in group B, with no significant difference between the groups at any of the follow-up visits, as shown in Table 3. Comparing the results for the conventional and sutureless groups, there was a statistically significant difference between the groups $(P<0.05)$, with higher comfort scores in the sutureless group. After the first month, the change was no longer statistically significant $(P>0.05)$ and remained so until month 6 . Two cases $(6.6 \%)$ in the conventional group developed suture-related granuloma.

\section{Wound leakage}

There were no cases of wound leak in either the conventional silicon-filled or conventional air-filled group. In the sutureless group, there was intraoperative wound leak in two cases $(6.7 \%)$ in group A which required suturing and in one case $(3.3 \%)$ in group B; the difference between the groups was not statistically significant $(P>0.05)$. Comparing the results in both the conventional and the sutureless groups, a statistically significant difference was found $(P<0.05)$,
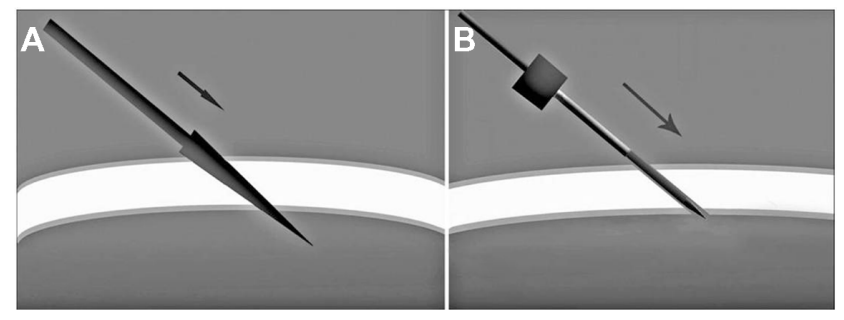

Figure 2 Angle of attack in the wound configuration. Notes: Wound entry using MVR (A), Wound entry using the trocar cannula system (B). with higher degrees of wound leak in the sutureless group. After the second week, the change became statistically insignificant $(P>0.05)$ and remained so until month 6. There was no wound leak at follow-up visits in either group. No cases of hypotony, endophthalmitis, or unsealed sclerotomies were observed during the study.

\section{Discussion}

Transconjunctival 20-gauge techniques have been described by Shimada et al ${ }^{11}$ and Gotzaridis, ${ }^{12}$ but were not sutureless, requiring one single suture for both the conjunctiva and sclera at the end of the procedure. The technique presented in this paper entailed the valved cannulated system devised by Claes which enables better access to incoming instruments with no need for diathermy over the conjunctiva or suturing of the conjunctiva and sclera at the end of the procedure.

A trocar system for 20-gauge instruments could be useful to avoid vitreous incarceration in the sclerotomy, provide a better entry path for vitrectomy instruments, with a shorter intraoperative time and rapid visual rehabilitation, less postoperative astigmatism, and a better postoperative appearance. Disadvantages of the trocar system include the longer intraoperative time, a slightly higher risk of scleral wound trauma, and the increased cost of the surgery. ${ }^{13,14}$

Spierer et al ${ }^{15}$ reported their outcomes using 20 -gauge transconjunctival sutureless vitrectomy and found no trocarrelated intraoperative complications. Two patients (2\%) each required suturing of their sclerotomy because of wound leak on completion of surgery. Mean preoperative intraocular pressure was $14.7 \pm 5.1 \mathrm{mmHg}$, and was $14.2 \pm 5.5 \mathrm{mmHg}$ on day 1 and $14.6 \pm 4.3 \mathrm{mmHg}$ on day 7 after surgery. Hypotony was present in three patients (3\%) on the first postoperative

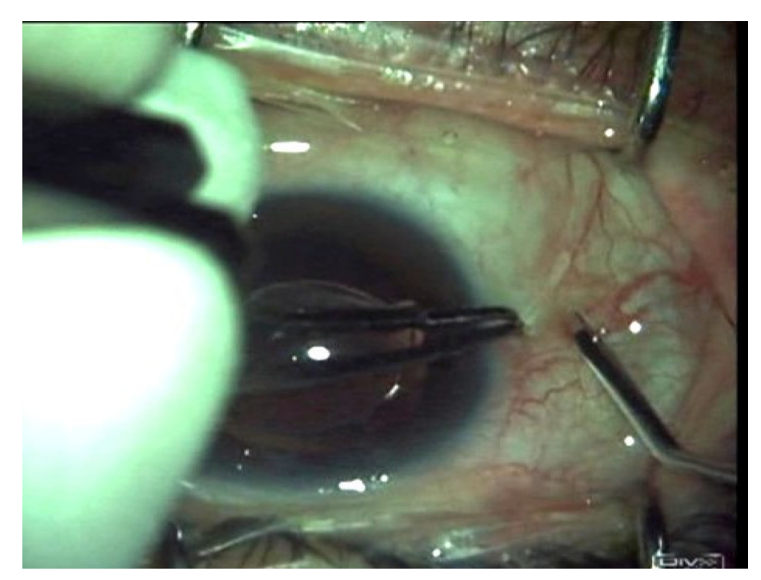

Figure 3 Intraoperative view showing the 15-degree angle direction with a bent MVR. Note: The conjunctival dragging.

Abbreviation: MVR, micro-vitreoretinal. 


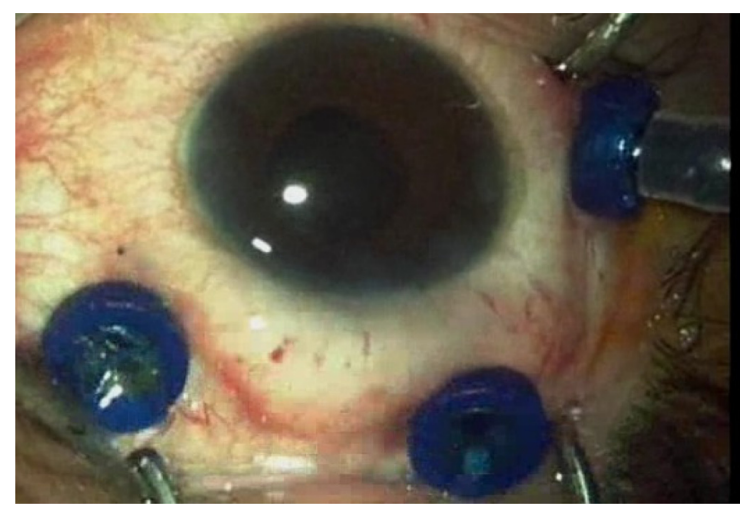

Figure 4 Intraoperative view showing the appearance after insertion of the threevalved trochar-cannula system.

day, but their intraocular pressure normalized spontaneously within one week. No patient developed postoperative endophthalmitis or retinal detachment. Spierer et al concluded that 20-gauge transconjunctival sutureless vitrectomy is a safe and effective technique for the surgical treatment of a variety of vitreoretinal pathologies. ${ }^{15}$

Our study included two cases $(6.7 \%)$ of intraoperative wound leak in the silicone-filled group and one case (3.3\%) in the air-filled group which required suturing, amounting to three cases $(5 \%)$ overall requiring sutures. Intraocular pressure increased from $17.67 \pm 5.6 \mathrm{mmHg}$ preoperatively to $18.78 \pm 6.1 \mathrm{mmHg}$ on the first postoperative day in group A and decreased from $16.97 \pm 4.9 \mathrm{mmHg}$ preoperatively to $15.88 \pm 5.3 \mathrm{mmHg}$ on the first postoperative day in group B. These differences were not statistically significant $(P>0.05)$, but the difference was significant in the second week and significant at months 2,4 , and 6 , with group A recording higher intraocular pressures than group B.
Postoperative hypotony was not noticed in any of our silicone-filled or air-filled eyes, which is in contrast with the series reported by Gotzaridis, in which hypotony was found on the first postoperative day because of minimal leak from one of the wounds, that returned to normal 3 days later as a result of the healing process at the scleral tunnel incision. ${ }^{12}$ Our series had no cases of postoperative vitreous hemorrhage in either group in comparison with the study reported by Aguni et al, which showed mild vitreous hemorrhage in 25\% of cases; however, these all spontaneously cleared up within weeks. ${ }^{14} \mathrm{We}$ also had no cases of vitreous incarceration at the sclerotomy, whereas Aguni et al did have one case of this. ${ }^{14}$

It is very important that all vitreoretinal surgeons use the same familiar instruments. These instruments are stiff enough to rotate the globe and their wider bore allows rapid vitrectomy and fluid exchange. Lee et a ${ }^{16}$ reported their comparison of 20-gauge transconjunctival sutureless vitrectomy with conventional vitrectomy, and observed that 89 of 107 sclerotomies $(83.2 \%)$ in their transconjunctival sutureless vitrectomy group self-sealed without the need for sutures. Their transconjunctival sutureless vitrectomy group showed earlier visual improvement from baseline, as early as 7 postoperative days, compared with 60 days in the conventional group. This was attributed to less surgically induced astigmatism in the transconjunctival sutureless vitrectomy group. No serious complications, such as postoperative hypotony, wound leakage, or endophthalmitis, were observed in either group. Their conclusion was that the 20-gauge transconjunctival sutureless vitrectomy technique is as effective as the conventional technique and offers earlier postoperative recovery.

In our study, keeping all the advantages of the sutureless system, we found that both the conventional and the

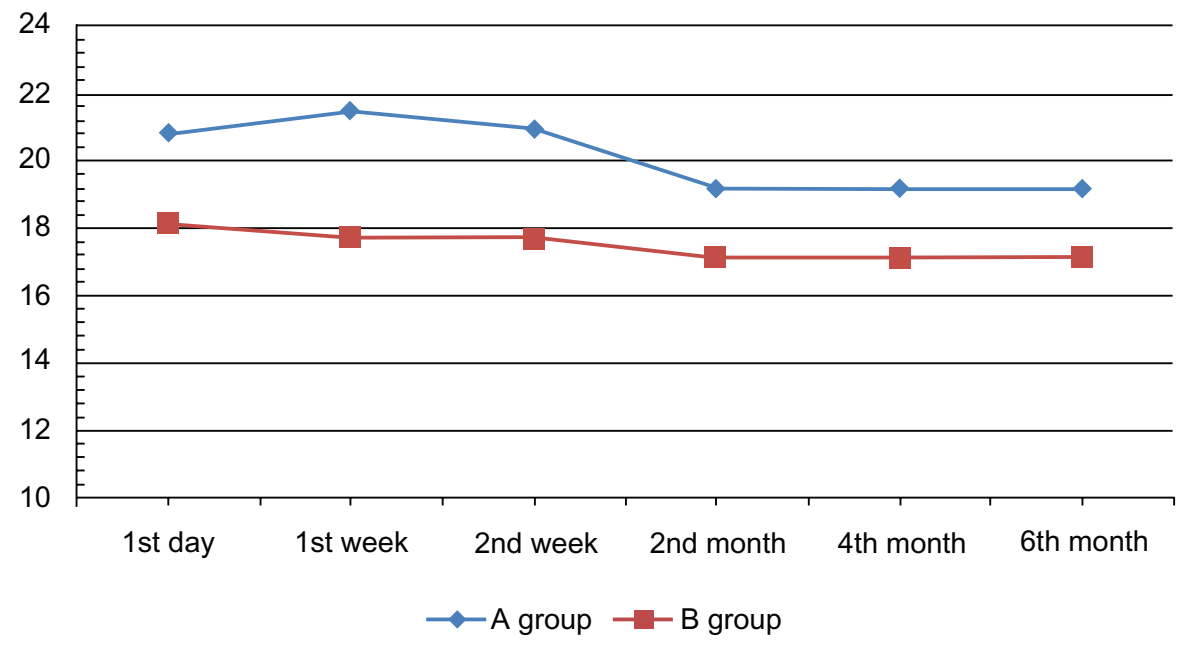

Figure 5 Difference between the mean intraocular pressure in study groups A and B during the follow-up period. 
Table 3 Differences in mean comfort scores between the sutureless groups during the follow-up period

\begin{tabular}{|c|c|c|c|}
\hline Comfort score & $\begin{array}{l}\text { Group A } \\
\text { (silicone-filled) }\end{array}$ & $\begin{array}{l}\text { Group B } \\
\text { (air-filled) }\end{array}$ & $P$ \\
\hline \multicolumn{4}{|l|}{ First day } \\
\hline Range & $2-5$ & $\mathrm{I}-5$ & $t=0.16$ \\
\hline Mean \pm SD & $4.4 \pm 0.94$ & $4.35 \pm 0.99$ & $P=0.8706$ \\
\hline \multicolumn{4}{|l|}{ First week } \\
\hline Range & $4-5$ & $3-5$ & $\mathrm{t}=0.90$ \\
\hline Mean \pm SD & $4.75 \pm 0.44$ & $4.6 \pm 0.59$ & $P=0.3736$ \\
\hline \multicolumn{4}{|l|}{ Second week } \\
\hline Range & $4-5$ & $4-5$ & $t=0.87$ \\
\hline Mean \pm SD & $4.8 \pm 0.4 \mathrm{I}$ & $4.9 \pm 0.31$ & $P=0.3888$ \\
\hline \multicolumn{4}{|l|}{ Second month } \\
\hline Range & $5-5$ & $5-5$ & $\mathrm{t}=0$ \\
\hline Mean \pm SD & $5 \pm 0$ & $5 \pm 0$ & $P=1$ \\
\hline \multicolumn{4}{|l|}{ Fourth month } \\
\hline Range & $5-5$ & $5-5$ & $\mathrm{t}=0$ \\
\hline Mean $\pm S D$ & $5 \pm 0$ & $5 \pm 0$ & $P=1$ \\
\hline \multicolumn{4}{|l|}{ Sixth month } \\
\hline Range & $5-5$ & $5-5$ & $\mathrm{t}=0$ \\
\hline Mean \pm SD & $5 \pm 0$ & $5 \pm 0$ & $P=1$ \\
\hline
\end{tabular}

Abbreviation: SD, standard deviation.

sutureless groups differ only in the first 2 weeks, with a higher degree of intraocular pressure and wound competence in the conventional group, which was statistically insignificant. The sutureless group showed better comfort scores during the first month, with rapid visual rehabilitation.

Once the patient benefits are clear, the issue of costbenefit also requires attention, and this is an issue of major concern for most health care systems. In one large teaching center, the cost of sutureless microincision vitrectomy surgery was calculated to be 3.4 times higher than that of sutured 20 -gauge vitrectomy surgery. While shorter surgery times have the potential to reduce costs, this has to be offset against the higher cost of sutureless systems, and the considerable investment that has already been made in 20 -gauge instruments in many centers. ${ }^{17}$

\section{Conclusion}

We found that transconjunctival cannulated sutureless 20-gauge surgery is an efficient, safe, and rapid approach for a variety of vitreoretinal disorders, with shorter postoperative recovery time, less postoperative corneal astigmatism, and

Clinical Ophthalmology

\section{Publish your work in this journal}

Clinical Ophthalmology is an international, peer-reviewed journal covering all subspecialties within ophthalmology. Key topics include: Optometry; Visual science; Pharmacology and drug therapy in eye diseases; Basic Sciences; Primary and Secondary eye care; Patient Safety and Quality of Care Improvements. This journal is indexed on rapid postoperative visual rehabilitation, and no need for changing instrumentation and the disposables that reflect the final cost.

Moreover, keeping virgin conjunctiva plays an important role in the management of postoperative glaucoma.

\section{Disclosure}

The authors report no conflicts of interest in this work.

\section{References}

1. Fujii GY, De Juan E Jr, Humayun MS, et al. A new 25-gauge instrument system for transconjunctival sutureless vitrectomy surgery. Ophthalmology. 2002;109:1807-1812.

2. Machemer R, Hickingbotham D. The three-port microcannular system for closed vitrectomy. Am J Ophthalmol. 1985;100:590-592.

3. Hilton GF. A sutureless self-retaining infusion cannula for pars plana vitrectomy. Am J Ophthalmol. 1985;99:612.

4. Mason G, Sullivan JM, Olk RJ. A sutureless self-retaining infusion cannula for pars plana vitrectomy. Am J Ophthalmol. 1990;110: 577-578.

5. Chen JC. Sutureless pars plana vitrectomy through self-sealing sclerotomies. Arch Ophthalmol. 1996;114:1273-1275.

6. Assi AC, Scott RAH, Charteris DG. Reversed self-sealing pars plana sclerotomies. Retina. 2000;20:689-692.

7. Kim MJ, Park KH, Hwang JM, Yu HG, Yu YS, Chung H. The safety and efficacy of transconjunctival sutureless 23-gauge vitrectomy. Korean $J$ Ophthalmol. 2007;21:201-207.

8. Eckardt C. Transconjunctival sutureless 23-gauge vitrectomy. Retina. 2005;25:208-211.

9. Rizzo S, Genovesi-Ebert F, Murri S, et al. 25-gauge, sutureless vitrectomy and standard 20-gauge pars plana vitrectomy in idiopathic epiretinal membrane surgery: a comparative pilot study. Graefes Arch Clin Exp Ophthalmol. 2006;244:472-479.

10. Fekrat S, Elsing SH, Raja SC, Campochiaro PA, de Juan E Jr, Haller JA. Eye pain after vitreoretinal surgery: a prospective study of 185 patients. Retina. 2001;21:627-632.

11. Shimada H, Nakashizuka H, Nakajima M, Mori R, Mizutani Y. Twenty gauge transconjunctival vitrectomy. Jpn J Ophthalmol. 2005; 49:257-260.

12. Gotzaridis EV. Three-port 20-gauge transconjunctival pars plana vitrectomy. Retina. 2007;27:382-384

13. Gotzaridis EV. Sutureless transconjunctival 20 gauge pars plana vitrectomy. Semin Ophthalmol. 2007;22:179-183.

14. Aguni JS, Meyer CH, Rodrigues EB. Transconjunctival 20-gauge vitrectomy: a pilot study. Ophthalmologica. 2009;223:12-16.

15. Spierer O, Siminovsky Z, Loewenstein A, Barak A. Outcomes of 20-gauge transconjunctival sutureless vitrectomy. Retina. 2011;31: $1765-1771$

16. Lee JE, Kim KH, Kim IK, Jea SY, Kim WS. Comparison of 20-gauge transconjunctival sutureless vitrectomy with conventional vitrectomy. Retina. 2010;30:1496-1504.

17. Lewis H. Sutureless microincision vitrectomy surgery: unclear benefit, uncertain safety. Am J Ophthalmol. 2007;144:613-615.

\section{Dovepress}

PubMed Central and CAS, and is the official journal of The Society of Clinical Ophthalmology (SCO). The manuscript management system is completely online and includes a very quick and fair peer-review system, which is all easy to use. Visit http://www.dovepress.com/ testimonials.php to read real quotes from published authors. 